\title{
When universal access is not quite universal enough: case studies and lessons to be learned
}

\author{
Simeon Keates ${ }^{1}[0$
}

Published online: 16 October 2018

(c) The Author(s) 2018

\begin{abstract}
While the theory of designing for Universal Access is increasingly understood, there remain persistent issues over realising products and systems that meet the goal of being accessible and usable by the broadest possible set of users. Clearly, products or services that are designed without even considering the needs of the wider user base are implicitly going to struggle to be universally accessible. However, even products that have been designed, knowing that they are to be used by broad user bases frequently still struggle to achieve the ambition of being universally accessible. This paper examines a number of such products that did not achieve, at least initially, the desired level of universal accessibility. Principal recommendations from each case study are presented to provide a guide to common issues to be avoided.
\end{abstract}

Keywords Universal access $\cdot$ Robots $\cdot$ Kiosks $\cdot$ Digital television $\cdot$ HCI $\cdot$ Input systems

\section{Introduction}

The need for universal access (UA) is well established across the globe [1] and is reinforced through legislation in many countries [2].

The theoretical basis for achieving universally accessible products is becoming well established and mature [3]. Most approaches to UA are derived from earlier work in the field of usability by such notable authors as Nielsen [4], Shneiderman [5], and Norman [6]. Their work, in turn, followed that from research centres such as Xerox PARC [7].

Early usability texts focused almost exclusively on able-bodied users and attention to users with functional impairments was comparatively rare. However, as usability methods matured, they began to extend to include accessibility issues that had, up to this point, been considered to be a separate design domain [8]. Different approaches were developed at this time, with different names, such as Universal Design (typically in the US and Japan) (e.g., [9]), Inclusive Design (typically in Europe) (e.g., [10]) and Design for All (also Europe) (e.g., [11]) and these came from different geographical regions, cultures, and application areas, such

Simeon Keates

s.keates@gre.ac.uk

1 University of Greenwich, Medway Campus,

Chatham Maritime, Kent ME4 4TB, UK as buildings access, IT equipment, or government services. However, all these approaches had a number of common features, including:

- understanding the user wants, needs, and aspirations [8], i.e., what they basically want to accomplish (note-these need not be task driven, but can be focused on experiences or sensations, for example);

- understanding the context of use, i.e., when and where it is to be accomplished;

- involving users in the design process, e.g., through participatory design or critical user forums [12].

Second generation methods, such as Countering Design Exclusion (CDE) and user-sensitive design [13] add to or augment these methods, for example:

- understanding where problems lie with the existing designs, so that designers can focus on areas with the known issues or deficiencies in terms of accessibility and usability (CDE) [8],

- using actors or other representatives/representations of the users to help designers where users may not be available for participatory design (pioneered by the team that developed user-sensitive design) [13], or,

- using simulations to provide greater understanding (what can be thought of as simulation-assisted design) [14]. 
However, while there is a substantial and still-growing body of work of how such design ought to be undertaken to achieve an effective Universal Access solution, the reality is that many products are still far from universally accessible [15]. This paper explores examples that were intended to be usable and accessible by the widest possible user base, though failed to achieve their goal. The examples will cover many areas of functional impairments, whether motor function, vision, hearing or cognitive, and areas of life endeavour [16], rather than focusing solely on computer access. However, the first examples will come from that field.

\section{Novel computer access systems}

It has long been known that the typical keyboard and mouse arrangement for computer access is innately problematic for those with moderate-to-severe functional impairments, whether motor impairments or poor vision [17]. Substantial research resources have been applied to the issues, with solutions ranging from very low-tech solutions, such as keyguards and large keyboards, to very high-tech ones, such as speech recognition, eye-gaze control, and advanced word prediction (e.g., $[18,19])$. Improved computer processor power and many years of development of the underlying models and algorithms have improved the reliability of such sources of inputs notably from their earlier incarnations. However, the keyboard and mouse still dominate most human-computer interaction [20]. It is interesting to explore why, even with the advent of near ubiquitous devices that lack keyboards, such as smart phones and tablets. There is a thriving market in keyboard accessories for devices that were designed for direct interaction with on-screen elements.

An example of why these other technologies rarely manage to displace the keyboard and mouse fully can be found in the development of Jester, a prototype gesture recognition system developed some time ago [21]. The results from that system are as valid today as they were then.

Users typically consider how well a system performs on three criteria when assessing whether it meets their needs or not:

- efficiency, i.e., the time taken and effort expended to complete a task;

- effectiveness, i.e., the ability to complete the task;

- satisfaction, i.e., user contentedness with the interaction.

Methods for calculating these measures have been formally proposed by the International Standards Organization [22]. Many system designers, though, rarely consider all three of these attributes when evaluating their designs. For example, those developing new computer input systems often focus only on the recognition rate of the software, i.e., what proportion of the input is recognized correctly by the system. However, while the recognition rate is clearly very important, it represents only one contributing element to the three metrics described above, meaning that other elements are being disregarded.

Jester was developed as a means of enabling users with moderate-to-severe motor impairment to interact with a computer via head and/or hand gestures [23]. The initial results showed that gesture recognition rates of over $90 \%$ could be obtained with practice and a small vocabulary of input gestures (left, right, up, down, yes/no, and no/shake) [21]. Much research at the time would have stopped at that point to report the results in the hope that a means of commercialization could then be found. The research team for Jester did not stop there, though. Figure 1 shows Jester being used with both head and hand input by a user with muscular dystrophy.

When Jester was tested by a hospital-based occupational therapy service [24], they appreciated the novelty of the input, but reported that the users were not sufficiently impressed to consider replacing their existing input systems, such as binary switches, with the new system even though it appeared to offer more freedom and flexibility. Further investigation revealed that, while the recognition rate was considered satisfactory, the effort required to produce controlled gestures that Jester could recognize was considerable. In addition, the time taken to produce and recognize the gestures meant that the throughput, i.e., the rate of useful information transfer between the user and the computer, was lower than for a simple binary switch that took minimal effort to control, was very configurable to a user's personal needs and required very little training to master [25]. The cost of the Jester system was also considered prohibitive.

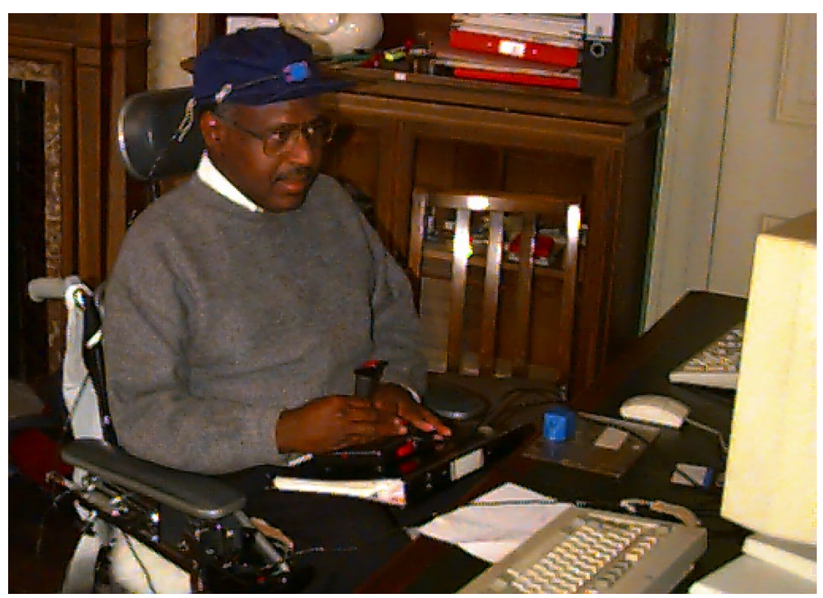

Fig. 1 Jester in use. Note the plastic cube mounted on the baseball cap for head gestures and the analogue joystick for hand gesture. Both could be used independently or combined 
Attempts to improve the throughput by increasing the usable input gesture vocabulary by combining head and hands gestures proved counter-productive. The cognitive and physical demands placed upon the users were increased significantly to the point where the interaction rate and throughput actually decreased [20]. Gesture recognition is nowadays largely the province of stylus input rather than head-and-hand movements. Even these had early mis-steps, such as the Apple Newton [26].

The most notable exceptions to this trend are to be found in gaming systems, such as the Nintendo Switch and Microsoft Kinect, and some smartphone apps, where system developers have identified tasks and activities that are inherently analogue in nature, such as swinging a virtual tennis racket, and are now being explored for use in universal access applications [27]. Newer examples include applications where users need their hands or attention for other purposes, for example the development of gesture input for in-vehicle control systems, where drivers can keep their eyes on the road ahead and make freeform gestures to control the in-car control system [28].

There are three key conclusions that can be drawn from the Jester prototype for outcomes that are to be avoided:

1. do not develop solutions that are too expensive, especially where cheaper options are available;

2. do not develop solutions that fail to consider all elements of the interaction or focus only on one element of it;

3. do not develop solutions that place too many demands (whether physical, sensory or cognitive) on the user.

\section{Improving the effectiveness of existing input systems}

Sometimes novel solutions for enabling universal access to computer systems can be found from products designed for other uses. One such example was the Logitech Wingman Force Feedback Mouse [29] —henceforth referred to as the Wingman mouse (see Fig. 2). This mouse was developed to enrich gaming experiences by supporting haptic force feedback through the use of a toolkit developed by Immersion. The toolkit enabled the mouse to emulate the feeling of moving over a tactile landscape where the edges of windows could be felt by a small judder of the mouse, for example. Gravity effects could also be added to on-screen elements, actively pulling the cursor into the elements [30].

While such effects can be achieved using solely visual feedback, whereby the cursor moves on its own, users typically find such assistance somewhat disorienting as it breaks the relationship between what their eyes see (the cursor location on screen) and their hands/arms feel (the position of the mouse under their hand). The Wingman mouse solved

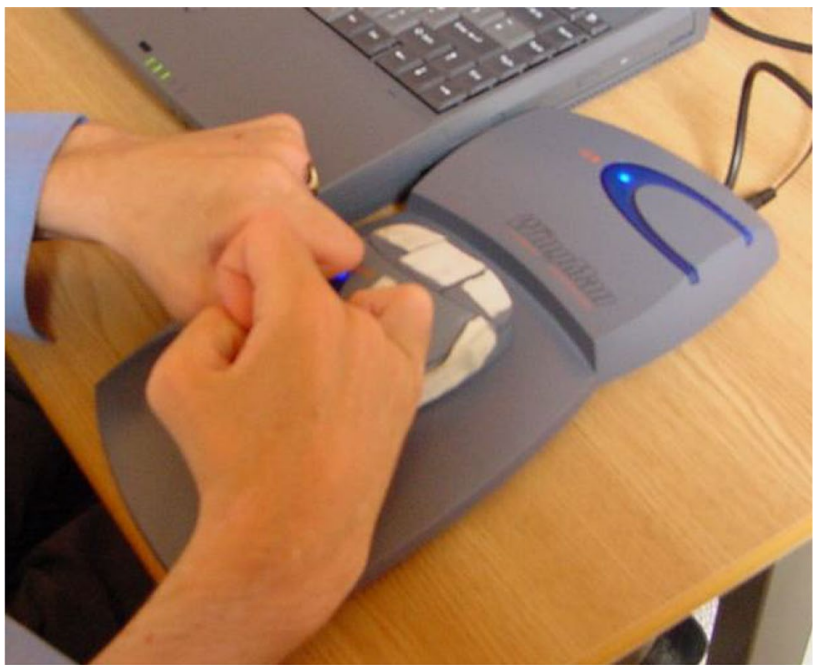

Fig. 2 Wingman Force Feedback mouse being used by a user with cerebral palsy. Note the user's curled fingers and the hockey tape added to the buttons to stop the user's fingers slipping off them

this issue by actually moving the mouse autonomously. The mouse had a metal pin under it that was connected to three motors via three cables arranged $120^{\circ}$ apart. The mouse was capable of exerting directional forces of up to $10 \mathrm{~N}$, i.e., sufficient to move a $1 \mathrm{~kg}$ weight.

User trials were conducted with a range of users with severe motor impairments arising from conditions such as cerebral palsy and muscular dystrophy. Using the Wingman mouse in conjunction with on-screen haptic gravity wells improved the average throughput across all the motorimpaired users to something broadly comparable with ablebodied users using an unmodified mouse [25]. Given the level of impairment of the users, this was an astonishing result and offered great potential for improving computer access for many users.

However, Logitech then withdrew the mouse and replaced it with one that had a small oscillator inside it, which could only simulate vibratory output and not move the mouse autonomously. This was extremely unfortunate for those users who stood to benefit from the technology. Informal enquiries found that the reason the mouse was withdrawn was probably connected to a legal case in the US where the parents of a child who had allegedly developed repetitive strain injury from playing on a Sega Rumblepad for several hours a day. Since the forces generated by the Wingman mouse were substantially greater than the Rumblepad, Logitech apparently withdrew the product and replaced it with a re-engineered one as a precautionary measure against possible litigation. The company that developed the underlying technology for the Wingman, Immersion Corporation, acknowledged the potential risk on litigation to the development of haptic input, specifically: 
"In the past, manufacturers of peripheral products, such as computer mice, have been subject to claims alleging that use of their products has caused or contributed to various types of repetitive stress injuries, including carpal tunnel syndrome. We have not experienced any product liability claims to date. Although our license agreements typically contain provisions designed to limit our exposure to product liability claims, existing or future laws or unfavourable judicial decisions could limit or invalidate the provisions" [31].

It is worth noting that almost any manufacturer of computer peripherals could have included such a statement in their financial reports and so immersion is not unique in this concern by any means.

More recent solutions to haptic input approach this thorny issue by:

- reducing the strength of the effect: e.g., later versions of the Wingman mouse, rebranded to the iFeel mouse, had a much smaller vibrating motor in them [32];

- targeting much larger and stronger parts of the body: e.g., gaming chairs where the entire back of the body is subject to vibration and whole-body haptic suits, rather than localised extremities of the body [33];

- making the experience less immersive: e.g., the Phantom haptic devices where the user holds a stylus to experience the haptic effect rather like using a pen to feel an object instead of ones fingers [34].

The conclusion to be drawn from these examples is:

4. do not develop solutions without considering the risks that may be presented to the users.

\section{Introducing new interaction paradigms}

Looking further afield than computer access, other systems rely upon software-mediated interaction, such as kiosks, information points, and smart televisions. One research study into the design of digital set-top boxes, undertaken just prior to the switchover of from analogue to digital television provision in the UK, highlights some of the issues that can arise where development focuses on the hardware and not on the software.

Prior to the digital switchover, televisions were capable of receiving the analogue signals from an external aerial and could be controlled by a straightforward infrared remote control. After digital switchover, viewers would either have to purchase a new integrated television that could receive and process the digital signals or else purchase a separate set-top box that would change the digital signals into analogue ones that the older televisions could display. Using a set-top box would necessitate the use of a second remote control.

The UK Department of Trade and Industry was concerned that switching off analogue TV signals would lead to some viewers being unable to watch the new digital-only services [35]. They commissioned a company, Scientific Generics, to investigate how many people may potentially have been excluded by the digital switchover. The initial approach to the challenge was to recruit users with significant functional impairments, such as deafness and blindness, to use a range of the new set-top boxes. However, after discussions with specialists in inclusive design, the aim was adjusted to identify users at the boundary of being able to use the new boxes. The idea was that if you could identify those who could just use the system, anyone with more severe functional impairments would most likely be unable to use it [36].

A number of older adults were recruited with a range of minor-to-moderate functional impairments (see Fig. 3), along with a number of younger users with more severe impairments. The results showed that while there were a number of physical access issues, the biggest causes of exclusion were cognitive in origin. Examples of the confusion were around the use of both remote controls, i.e., the one for the television and the one for the set-top box. To keep costs down, the set-top box designers used cheap generic remote controls that were not designed specifically for the boxes, but could be used to also control VCRs, DVD players, and televisions. As a consequence, both remote controls often looked to offer the same functions, but one operated some of them and the other operated the rest of them. The users often got confused over which did which. Newer designs for such boxes are now tailored specifically to set-top box operations.

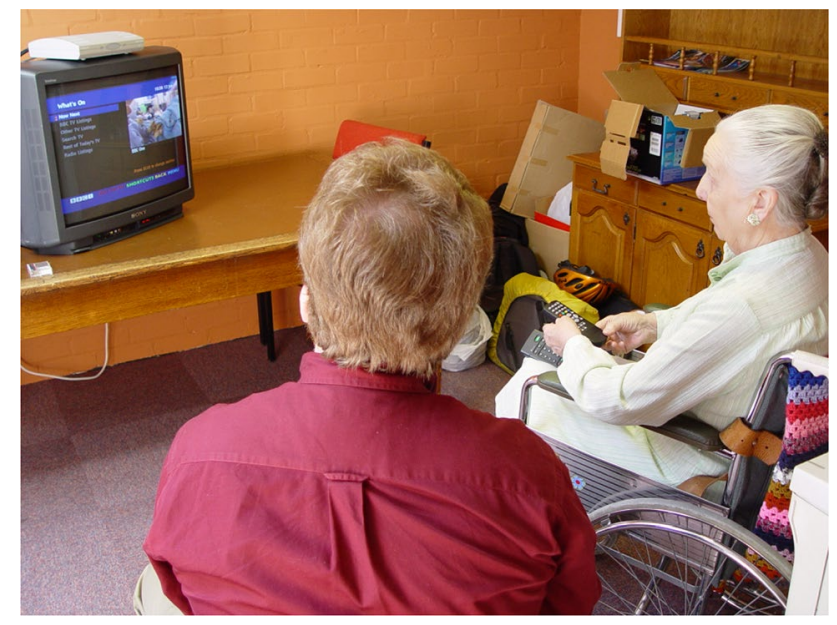

Fig. 3 Digital set-top box user trials. Note the pale grey box on top of the television set and the multiple remote controls on the user's lap 
Another area of exclusion was the software interface itself. As part of the user evaluation protocols, users were asked to complete a range of tasks including finding the local weather using the in-built teletext service used in the UK. The analogue teletext pages were structured around a page numbering system that allowed users to navigate either by typing in a three-digit page number directly or using four colour-coded "fastext" buttons to jump to common page choices. On Ceefax, the BBC's teletext service, page 100 (the first page) is an index page and each of the " 00 " pages was the index page for that subsection. For example, pages 100-199 were usually for news, pages 200-299 were for finance, and 300-399 were sport, etc. Viewers typically learned the page numbers for their preferred pages, such as page 400 for the weather subsection, or else used the fastext buttons to follow the recommended links to get there.

On the digital television service, the inherent search space was no longer so obviously analogous to navigating a book with sections and subsections. There were no page numbers displayed on the screen and viewers could only navigate using prompts or the cursor keys on the remote control. The mental model used for the navigation was based on web pages, which do not typically use a page numbering system and support much more flexible navigation. This new approach made sense to the designers, who were clearly web-savvy computer users.

However, the older adults in the user session became very confused where they were in the digital teletext service, because this was a completely new way of navigating information and had no signposting to indicate where they were or how they had got there, unlike the old page number system. Following the results of this investigation, page numbers were reintroduced and the older adults found the new design far more usable. It is as important to consider cognitive aspects of interaction as it is to look at the physical ones [37].

The conclusions from the DTV case study are:

5. do not use inappropriate interaction paradigms;

6. take time to understand the users-their background, knowledge, and experience.

\section{Robotic universal access assistants}

As discussed earlier, in the early stages of the development of any new and innovative product, the focus is principally on developing the new technology, especially overcoming the inherent engineering challenges to make something that accomplishes the basic task set required [38]. Users typically get overlooked in this early stage of development, not least because if the engineering challenges are significant, there is no guarantee that a feasible product may ever be developed [39]. Instead, designers typically end up designing something that they themselves, regarding themselves as suitable substitutes for the actual end-users [40]. Consequently, the almost inevitable outcome is a product that works best for users who are most like the designer, including attributes such as their knowledge (both background knowledge and detailed knowledge of the product), experiences, capabilities, anthropometrics, and so on [41]. Those who are notably different, which those who would benefit most from a universal access-based approach usually are, do not fare so well. All of these challenges are difficult enough where the hardware platform is widely understood, such as in human-computer interaction. However, when developing systems that involve new hardware, the challenges faced increase.

For example, in the 1990s, the European Union funded a number of research programmes through its Telematics for the Integration of Disabled and Elderly people (TIDE) initiative to develop robotic assistants for users with severe functional impairments. Over $\$ 150 \mathrm{~m}$ was invested, supporting the development of solutions from office workstations to wheelchair-mounted robots [42]. However, the success of those robots and others developed under similar initiatives was far from satisfactory [43]. Table 1 shows the sales results recorded at the time. Only the Handy 1 robot arm [44] and MANUS wheelchair-mounted robot [45] achieved any degree of successful take-up. Fewer than ten of each of the other robots investigated were produced [43].

Looking at the two more successful robots, the Handy 1 was created by a small British start-up company with a view to being launched as a commercial product. It consisted of a generic robot arm mounted on a mobile base, allowing

Table 1 Some of the rehabilitation robots in the late 1990s and their comparative commercial success at that point in time [43]

\begin{tabular}{llllrr}
\hline Product name & Country & R\&D effort/support & Type & Approx cost & Numbers sold \\
\hline DeVar & USA & Boeing & Vocational workstation & $\$ 100,000$ & 3 \\
Manus & The Netherlands & IRV, TPD & Wheelchair-mounted & $\$ 35,000$ & 50 \\
RAID/EPI-RAID & UK, France, Sweden & EU TIDE & Vocational workstation & $\$ 55,000-\$ 250,000$ & 9 \\
Handy 1 & UK & Ltd co & Mobile base & $\$ 6000$ & 140 \\
Papworth Arm & UK & Inventaid & Wheelchair mounted & $\$ 8000$ & 5 \\
Arlyn Arm Workstation & USA & US DoE & Vocational workstation & $\$ 30,000$ & 0 \\
\hline
\end{tabular}


the design team to focus on the task and the user interaction rather than the development of a brand new robot arm. Attached to the arm was a simple spoon. The users' food was placed in five segregated sections of a tray and, through a straightforward interface, the users could feed themselves. This robot allowed many users to feed themselves independently for the first time in their lives. Thus, a real need had been identified and a reasonably cheap solution (ca. \$6000) developed. A second variant was introduced allowing users to apply make-up. Approximately 150 units had been sold by 1997 [43].

The MANUS robot was developed in the Netherlands and it was fundamentally a robot arm mounted on the side of a wheelchair. As such, the robot was inherently mobile, albeit with the disadvantage of making the wheelchair notably wider in certain configurations. The cost was significantly more than the Handy $1(\$ 35,000)$, but sales were helped by a pre-existing agreement between the development team and the Netherlands government, which was the largest buyer.

The typical causes of failure in the other robots were illustrated by the EPI-RAID workstation [39] (see Fig. 4). This robot was developed to help a user with severe motor impairments to move documents and books around an adapted office space. Like the Handy 1, it used a generic robot arm, but the arm was mounted on a gantry so it could move around the office space to pick papers and files from shelving and place them on a page-turning device for the user to read. Unlike the Handy 1, where the user sat close to the robot arm, so the range of movement required was limited, the EPI-RAID system needed to controllable at a greater distance, with a larger range of possible movement and needed greater accuracy. It also needed to support a

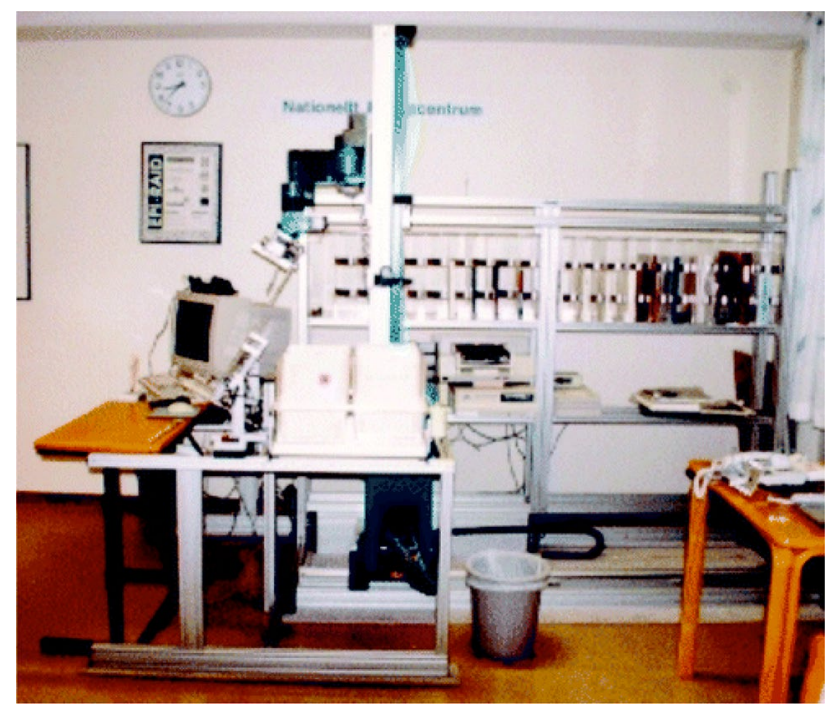

Fig. 4 EPI-RAID office workstation consisting of an RTX robot arm mounted on a gantry in a purpose-built office [46] wider variety of interactions as a direct consequence of the broader range of functional tasks that it was designed to support.

The focus on meeting the technical challenges of the robot, the gantry, and the grippers meant that the user interface was not addressed until quite late in the design process. Furthermore, the complexity of the engineering challenges pushed the cost of the overall system up to at least an order of magnitude more than the Handy 1 . User trials showed that the technical challenges of the robot had been met, but the user interface was too rudimentary to be useful. To improve, it would have required substantial redevelopment, with the commensurate costs that would have pushed the price of the system up even further. The final nail in the coffin was that EPI-RAID was overtaken by the other developments in technology. The emerging ready availability of CD-ROMs and the Internet shortly after the commencement of the project made information available on the computer directly without needing to manipulate hard copies, making the concept behind EPI-RAID somewhat redundant.

The other TIDE funded projects suffered from very similar issues, i.e., cost of the system, the time to develop them being too long, being superseded by new technologies and generally too little focus on the user interface, especially its usability and accessibility. The general conclusions to draw from these projects are:

7. do not focus on the development of the technology to the exclusion of consideration of the user;

8. develop solutions that meet genuine needs, wants and aspirations of the users;

9. allow enough development time to ensure the user interface is satisfactory.

\section{Access to information services}

Another set of projects that experienced similar issues to rehabilitation robotics come from almost a decade later and show that while the technology had changed, the underlying issues encountered largely had not.

The UK postal service, Royal Mail, was looking to make its post offices more high-tech and approached a number of suppliers to propose possible solutions to do so. Two solutions were put forward, the Personal Information Point [47] and the Your Guide kiosk [48]. Before these products were rolled out, Royal Mail commissioned user trials to establish whether they were sufficiently usable and accessible. Neither product was introduced following the identification of issues through those user trials.

The first solution, the Personal Information Point (PIPsee Fig. 5), had originally been developed for use in museums to help visitors navigate around the exhibits and also 


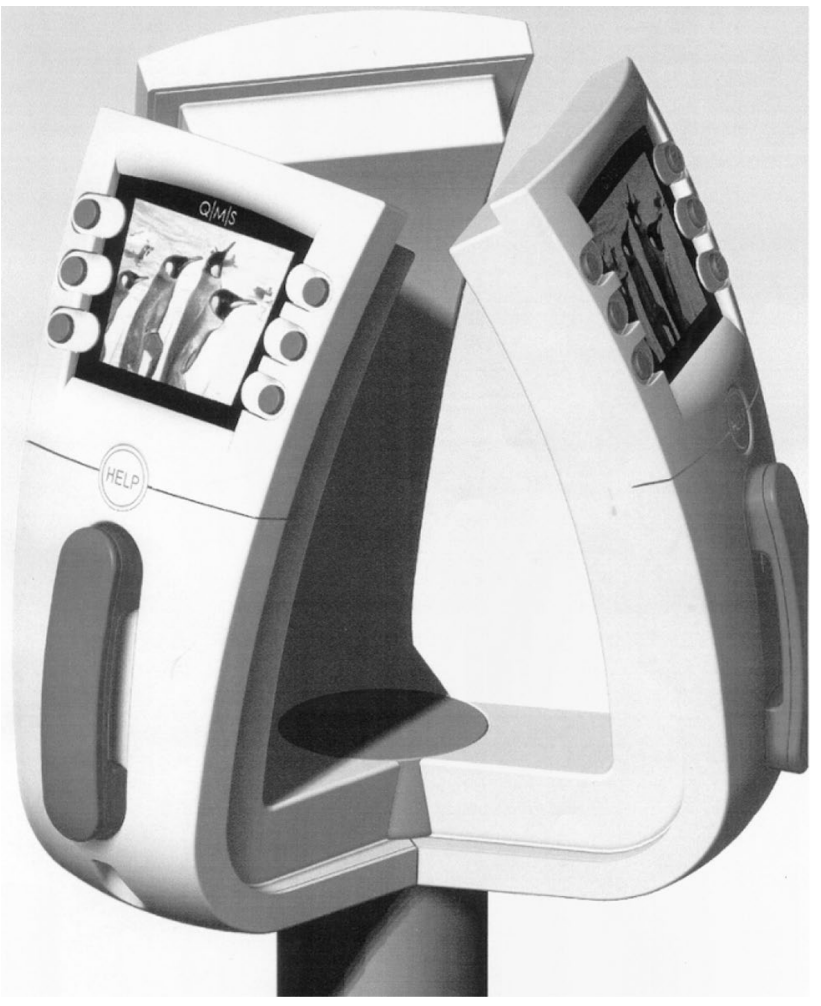

Fig. 5 Personal Information Point. Note the telephone handset for audio output, the LCD screen for visual output, and the six buttons arranged either side of the screen for input. To use the PIP, the user would have to be able to see the screen, hear the audio, and simultaneously hold the handset and press the buttons

provide more detailed information on those exhibits. It comprised 1-3 "heads" mounted on a fixed column. Each head held a small LCD panel, approximately $12 \mathrm{~cm}$ across, three buttons arranged on both the left- and right-hand edges of the screen and a telephone handset. The content on the screen could either be static text or video and any auditory output was provided via the telephone handset. It was straightforward to see how the PIP could be used in a museum context with this design.

However, the proposal was to use this same design in busy and noisier post office environments to provide detailed information about National Savings investments products, such as savings accounts, investment bonds, etc. These products are governed by regulatory rules that require lots of small print to be shown and are intrinsically complex. This was anticipated to result in several screens, worth of information needing to be displayed for each product as well as the ability to compare across products.

The design team was all comparatively young, male, ablebodied, and was not used to designing products of this type. The PIP represented something of a departure from their usual product ranges. The target users identified, though, were typical post office customers, with a particular focus on older ladies collecting their pensions. A pre-user trial analysis of the design was undertaken to evaluate where the issues might be expected when users attempted to interact with the PIP.

This pre-trial evaluation highlighted a broad range of issues. For example, the screen was positioned at such a height that while the young, male design team could see it, half the older, female users probably would not have done according to data from anthropometric standards. Similarly, the use of the telephone handset would have presented significant motor and hearing challenges from the requirement to hold the handset and listen to audio output in a fairly noisy environment. The small screen and requirement to display lots of text presented significant vision challenges as the text displayed would either have to be very small or else needed to be presented over multiple screens, which would then have posed memory and motor challenges instead. The use of the six buttons and their rather high location posed motor and dexterity problems with the users potentially needing to raise either arm to push them. The capability demands they would have been placed on the users were evaluated against the prevalence of capability data collected from the 1996/7 Disability Follow-Up Survey [49]—a national survey of ca. 8000 people to find out what capability limitations that they experienced on a regular basis. An online tool had been developed at the University of Cambridge [50] and an updated version is also available [51].

The results of the pre-study analysis were very surprising. Approximately half of the target population was anticipated to experience significant difficulties using the PIP just from the screen being too high and a quarter of all adult women (not just those over the age of 65) were anticipated to not be able to see the screen. Combining the anthropometric exclusion with the anticipated capability demands resulted in up to $45 \%$ of the UK adult population being potentially excluded without even beginning to look at the cognitive demands from the information being displayed on the screen [48].

Royal Mail did not proceed with the PIP and an alternative supplier proposed the Your Guide kiosk (see Fig. 6). This kiosk was much more traditional in design, comprising a large touchscreen positioned at a much lower height. Users could operate the kiosk while standing or seated. A separate "free-phone" telephone was provided adjacent to the kiosk. The kiosk was designed to provide access about the local town, including governmental and council services, utilities contacts, leisure facilities, and the like. While the kiosk overall was physically much more accessible than the PIP, the users still could not access the information easily. As with the digital television example earlier, the principal challenges were around some of the design choices, such as the layout of the on-screen keyboard, and the use of icons that the users did not understand. The designers had chosen to use fairly common computer icons, but the users in the 


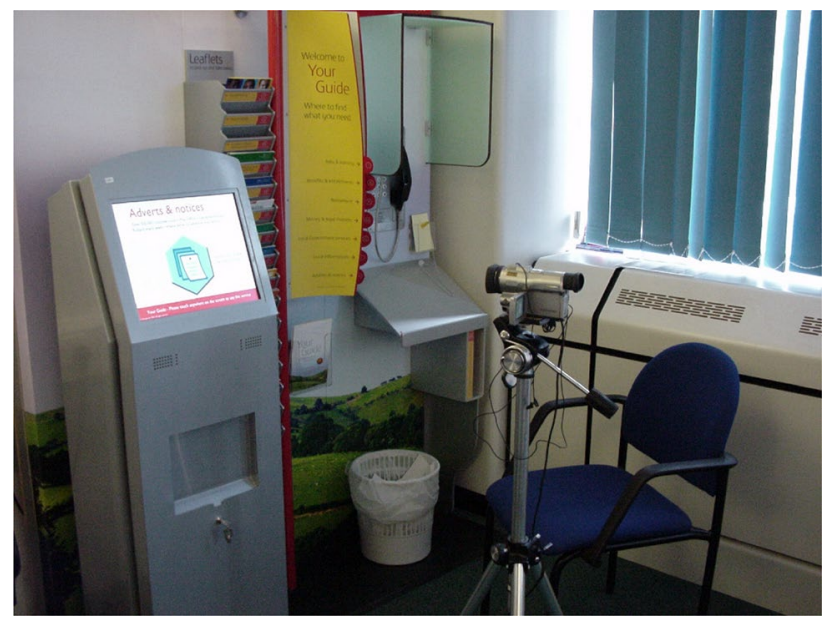

Fig. 6 The Your Guide kiosk, its surround and the free-phone telephone. Note the plastic shroud around the telephone and the black foam rubber that had to be added to stop taller people from hitting and hurting their heads

trial sessions were not regular computer users, so did not recognize or understand the more abstract icons.

There were still a number of physical access issues, especially for the telephone (see Fig. 7). The telephone cable hung across the keypad, the keys were soft, rubberized ones that needed to be pushed inwards and bent under the user's fingers, and a privacy surround had been added, but was too low so anyone slightly above average height would bang their forehead on it.

The combined conclusions from both kiosks were:

10. remember that designers and users are different. Be especially mindful of anthropometric diversities;

11. be careful about trying to adopt solutions that are applied outside of the primary use for which they were developed.

\section{Universal access throughout the interaction}

The final example is a fairly straightforward one. Even the best-designed products can be let down by a small, seemingly trivial detail possibly buried somewhere in the chain of interactions between a user and a product or service [52]. It is necessary to check all the stages of the interaction to ensure that all aspects are accessible.

For example, it is now possible to buy mobile phones (cell phones) with large keys for users with reduced vision and/or limited dexterity. One such example is shown in Fig. 8. The buttons are fairly straightforward to see for everyone with reasonable eyesight. However, Fig. 8 also shows a page from the instruction manual, where the font is notably smaller. While

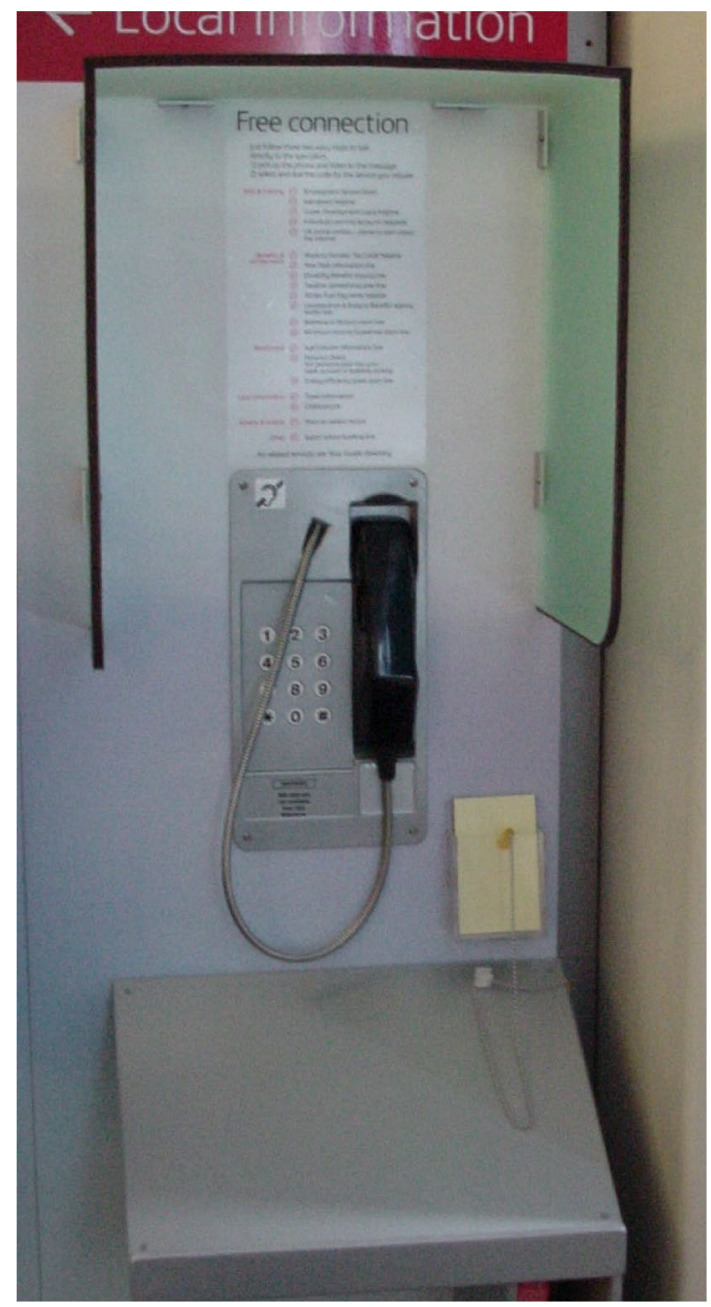

Fig. 7 The Your Guide telephone. Note the cable obscuring the sunken, rubberized buttons, and the black foam rubber bumper around the plastic shroud to protect against people bumping their heads on the hard plastic

this is probably not going to stop a user from being able to use the phone, it shows that the thinking process across all the aspects of the design of the product, which includes packaging and instructions, was not as complete as it might be.

The conclusion from this example is:

12. Remember to check all the stages of the interaction process from setup to decommissioning and ensure that they are all equally accessible.

\section{Summary}

This paper has examined a number of case studies where designers had striven to develop products to meet the needs of the widest possible sets of users, but had not 
Fig. 8 Big Button mobile phone and instruction manual. Note the disparity in size between the labels on the keypad and the size of font in the instructions

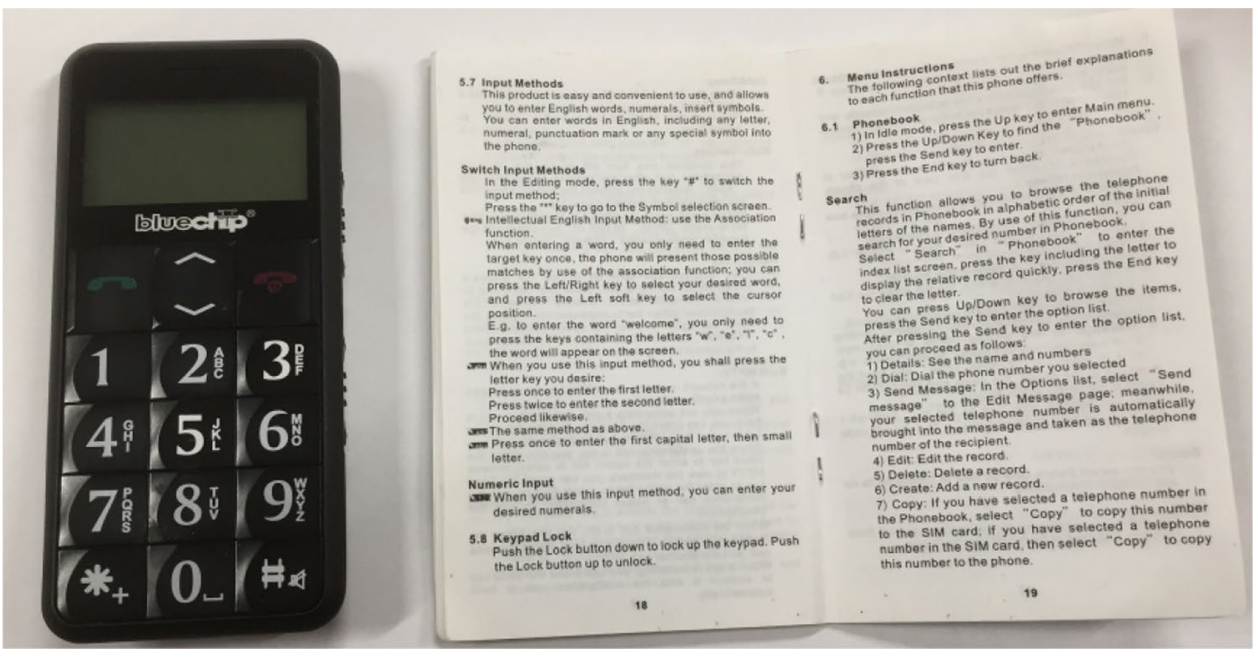

quite achieved the outcomes desired. Each case study highlighted different issues that, taken together, make for a useful set of reminders for all the designers:

1. do not develop solutions that are too expensive, especially where cheaper options are available;

2. do not develop solutions that fail to consider all elements of the interaction or focus only on one element of it;

3. do not develop solutions that place too many demands (whether physical, sensory or cognitive) on the user;

4. do not develop solutions without considering the risks that may be presented to the users;

5. do not use inappropriate interaction paradigms;

6. take time to understand the users - their background, knowledge, and experience;

7. do not focus on the development of the technology to the exclusion of consideration of the user;

8. develop solutions that meet genuine needs, wants, and aspirations of the users;

9. allow enough development time to ensure the user interface is satisfactory;

10. remember that designers and users are different. Be especially mindful of anthropometric diversities;

11. be careful about trying to adopt solutions that are applied outside of the primary use for which they were developed;

12. remember to check all the stages of the interaction process from setup to decommissioning and ensure that they are all equally accessible.

Of course, it is straightforward to list a collection of dos and do nots, but quite another to put them to good use. Guides, such as BS7000 [53], exist on methods for how to design inclusively and it is important to use the guidelines presented in this paper in conjunction with those methods and processes. One of the challenges with formal methods is that designers can get so engrossed in the process and trying to plan for the next stage of the method that they sometimes forget to take a step back and consider/reflect on the overall direction of travel of the design.

If the designer does take a step back to reflect and consider, it is helpful to have some idea of what to look for. The aim of the guidelines presented here is to support those moments of reflection and to provide a complementary set of rational checks to ensure that the design is not inadvertently heading towards a dead-end.

\subsection{Applying the guidelines}

Looking at each guideline in turn, it can be seen how they can be applied in practice when designing and developing new devices or products.

Guideline 1-Logitech was not the only company developing a mouse based on Immersion's haptic technology. A number of specialist assistive technology companies did the same. However, the Logitech mouse cost an average of $\$ 80-\$ 100$, whereas the specialist ones developed explicitly for users with motor impairments typically cost $\$ 1000$. Needless to say, very few were sold. Cost effectiveness simply cannot be ignored in most situations.

Guideline 2-examples of failing to consider all the aspects of interaction include developing auditory navigational assistants for people who are blind that require the user to wear headphones to hear the instructions, but that also simultaneously stop them from hearing approaching cars as they attempt to cross a street. Interaction with a device can incorporate many facets and stages, using a range of modalities and senses. Accessibility issues can arise in any of those facets or stages, so they must all be considered.

Guideline 3-it has to be borne in mind that many users with moderate-to-severe functional impairments often need 
to work extra hard to compensate for the impairments. As such, it becomes particularly difficult for them to cope with significant additional demands placed upon them by the device that they are trying to use. For example, asking a user with tremor to have to keep their hands still to complete a task is unlikely to be successful.

Guideline 4-as with guideline 3, users with moderateto-severe functional impairments are less likely to be able to avoid injury when using a product that is unsafe. It is particularly important to ensure that all avoidable risks and dangers are removed for the users.

Guideline 5-the definition of "inappropriate" and, by extension, "appropriate" paradigms is largely dependent on the task being considered. It is important to bear in mind that the more the interaction paradigm is based on the obvious options available to the users, the better it is for them. The problem highlighted in the digital television example given in this paper was that the designers had tried to import a computer interaction paradigm into am established television context and had made a little attempt to introduce the users to the new paradigm. It would have been better to extend the established interaction paradigm rather than try to introduce a wholly new one with no explanation and where it had no obvious connection to the task at hand. What may make sense for one person may not make sense for another person.

Guideline 6-as an extension of guideline 5 above, the use of the computer-based paradigm for the digital television example made sense for the designers, because they were presumably used to using computers, so the new paradigm made sense to them. However, the users who evaluated the set-top boxes were not experienced computer users, so the paradigm was both unknown to them and unrelated to the task. This was not the only example in this paper where designers had assumed that users were used to something, only to discover that they were not. The best way to avoid such problems is to get to understand the users more completely rather than blithely making assumptions about them. Approaches such as user-centred design and user-sensitive design have been developed precisely to avoid such issues.

Guideline 7-this guideline is primarily focused on ensuring that the designers remember the users, especially when developing a new technological solution that requires significant innovation and/or invention to make it work. There is a little point in developing an innovative new technology that the users will not use no matter how cool the new solution may be. It is under such circumstances, with heavy time-pressures and deadlines with a new technology that is stubbornly refusing to work that the needs of the users can be forgotten. However, to forget them will lead to a product or device that still will not work, albeit for different reasons, i.e., the user cannot use it rather than, because the technology was incomplete.
Guideline 8-the history of the development of new assistive technologies is littered with examples of products that seemed to be technologically sound, but simply do not take off in the marketplace. Usually, the reason is because the users just do not see the value in investing their money or their time and effort in buying, learning to use and maintaining the product or device. However, there are plenty of examples of devices that serve little useful purpose, but still sell very well, such as the Tamagotchi craze of the 1990s or loom bands a few years ago. The important point here is that the users need to see a value in the product or device to want to put the effort in to own one. Designers sometimes become convinced that a device or product will be purchased based solely on its technical merits, but that is rarely the case.

Guideline 9-the thought process that a new product needs to finish its technical development first and foremost and that the interface can be bolted on afterwards is still a difficult one to shake, no matter how many usability texts make it clear that this is not the correct way to proceed. Put simply, a product or device with a poor interface will still fail as badly as one that is incomplete technically, e.g., one that may not offer all of the desired functionality. The products that typically succeed best in the marketplace combine technical completeness, correct price point, and sufficient usability/accessibility. If a product does not offer all three features, it is likely to fail. It is better to adjust the development timeline to allow time for all the development to be completed sufficiently than to rush to market with major flaws. If the development of the technology is proceeding more slowly than expected, it is better to adjust timelines and project management than to just assume that the users will not notice a poor interface.

Guideline 10—put simply, if a design team is young and predominantly male, but the intended users are notably older and primarily female, there will be significant differences between the users and designers, such as their respective mean heights, strength and so on. Likewise, as people age, their irises typically become more yellow, making it harder to distinguish between yellow and white. It can be hard for one group of people to fully understand the capabilities and attributes of another group. One possible solution is the use of simulation aids to mimic the effects of impairments [14].

Guideline 11-as discussed earlier, users with functional impairments may struggle to complete certain tasks that those without the impairments may experience no difficulty with. This is the point at which impairment becomes disability. Sometimes users are able to adapt a product or device to meet their needs, but this is often a highly personal situation and not usually appropriate for many others. For example, there have been cases where people who are deaf and nonspeaking have found mobile telephones to be useful, but as a way of sharing text typed on them with those they are trying to communicate with, e.g., in a shop with a sales assistant 
who can also see the screen, rather than as a telephone for making calls. However, such instances are comparatively uncommon. More commonly, though, people with more profound functional impairments typically take more time to learn and adapt to new technologies. It is best to minimise the amount of superfluous learning effort wherever possible, so using devices that relate explicitly to the task at hand are likely to be more useful than those that are more general purpose. An example was the comparative usability of remote controls designed explicitly for use with a set-top box compared with the perceived poor usability of general purpose remote controls that had been re-programmed for use with such devices.

Guideline 12-guideline 2 addressed all the stages of interaction between the user and the product or device. However, while that guideline was focused more on the primary uses of the product, e.g., a remote control for watching television, it is also necessary to think more broadly about all aspects on the ownership life cycle of the product/device. For example, in addition to using the product/device, designers need to consider all the steps such as buying the product, unpacking it, setting it up (including programming it, where appropriate), decommissioning it, and ultimately disposing of it. Each of these steps has its own range of interaction processes and requirements and all of these need to be considered for the ownership experience to be a successful one for the user.

Open Access This article is distributed under the terms of the Creative Commons Attribution 4.0 International License (http://creativeco mmons.org/licenses/by/4.0/), which permits unrestricted use, distribution, and reproduction in any medium, provided you give appropriate credit to the original author(s) and the source, provide a link to the Creative Commons license, and indicate if changes were made.

\section{References}

1. Stephanidis, C.: The Universal Access Handbook. CRC Press, Boca Raton (2009)

2. Keates, S.: Designing for Accessibility-A Business Guide to Countering Design Exclusion. CRC Press, Mahwah (2007)

3. Clarkson, P.J., Coleman, R., Lebbon, C., Keates, S.: Inclusive Design-Design for the Whole Population. Springer, London (2003)

4. Nielsen, J.: Usability Engineering. Morgan Kaufmann, San Francisco (1994)

5. Shneiderman, B.: Designing the User Interface: Strategies for Effective Human-Computer Interaction. Addison-Wesley Longman, Boston (1997)

6. Norman, D.: Affordance, conventions and design. Interactions 6(3), 38-43 (1999)

7. Card, S., Moran, T.P., Newell, A.: The Psychology of HumanComputer Interaction. Lawrence Erlbaum Associates, Mahwah (1983)

8. Keates, S., Clarkson, P.J.: Countering Design Exclusion-An Introduction to Inclusive Design. Springer, London (2003)
9. Goldsmith, S.: Universal Design. Architectural Press, Routledge (2000)

10. Keates, S., Clarkson, P.J., Harrison, L.A., Robinson, P.: Towards a practical inclusive design approach. In: Proceedings of ACM Conference on Universal Usability (CUU 2000). ACM Press, New York, pp. 45-52 (2000). https://doi.org/10.1145/355460.355471

11. Stephanidis, C.: Design for all. In: Soegaard, M., Dam, R.F. (eds.) The Encyclopedia of Human-Computer Interaction, 2nd edn. The Interaction Design Foundation, Aarhus (2013)

12. Dong, H., Clarkson, P.J., Cassim, J., Keates, S.: Critical user forums-an effective user research method for inclusive design. Des. J. (Routledge) 8(2), 49-59 (2005). https://doi. org/10.2752/146069205789331628

13. Newell, A.F., Gregor, P., Morgan, M., Pullin, G., Macaulay, C.: User-sensitive inclusive design. Int. J. Univ. Access Inf. Soc. (UAIS) (Springer) 10(3), 235-243 (2011). https://doi.org/10.1007/ s10209-010-0203-y

14. Cardoso, C., Clarkson, P.J.: Simulation in user-centred design: helping designers to empathise with atypical users. J. Eng. Des. 23(1), 1-22 (2012)

15. Dong, H., Keates, S., Clarkson, P.J., Cassim, J.: Implementing inclusive design: the discrepancy between theory and practice. In: Proceedings of the 2002 ERCIM Workshop on User Interfaces for All, Lecture Notes in Computer Science, vol. 2615. Springer, Berlin, pp. 106-117 (2002). https://doi.org/10.1007/3-540-36572 $-9 \_8$

16. Keates, S., Kozloski, J., Varker, P.: Cognitive impairments, HCI and daily living. In: Proceedings of International Conference on Universal Access in Human-Computer Interaction. LNCS, vol. 5614. Springer, Heidelberg, pp. 366-374 (2009). https://doi. org/10.1007/978-3-642-02707-9_42

17. Trewin, S., Keates, S.: Computer access for motor impaired users. In: Encyclopedia of Human-Computer Interaction. IGI, London, pp. 92-99 (2006)

18. Ward, D.J., Blackwell, A.F., MacKay, D.J.C.: Dasher-a data entry interface using continuous gestures and language models. In: Proceedings of the 13th Annual ACM Symposium on User Interface Software and Technology (UIST'00), pp. 129-137 (2000). https://doi.org/10.1145/354401.354427

19. Goette, T.: Factors leading to the successful use of voice recognition technology. In: Proceedings of the 3rd International ACM Conference on Assistive Technologies (ASSETS'98), pp. 189-196 (1998). https://doi.org/10.1145/274497.274532

20. Trewin, S., Pain, H.: Keyboard and mouse errors due to motor disabilities. Int. J. Hum. Comput. Stud. 50(2), 109-144 (1999)

21. Keates, S., Robinson, P.: Gestures and multimodal input. Behav. Inf. Technol. (Taylor and Francis Ltd.) 18(1), 36-44 (1999). https ://doi.org/10.1080/014492999119237

22. International Standard Organization (ISO): ISO 9241-11: ergonomic requirements for office work with visual display terminals (VDTs), Part 11: Guidance on Usability Specification and Measures. In: Technical report. ISO, Geneva (1998)

23. Keates, S., Perricos, C.: Gesture as a means of computer access. Commun. Matters 10(1), 17-19 (1996)

24. Keates, S., Potter, R., Perricos, C., Robinson, P.: Gesture recognition-research and clinical perspectives. In: Proceedings of RESNA '97 (Pittsburgh, Pennsylvania). RESNA Press, Washington, pp. 333-335 (1997)

25. Keates, S.: Measuring acceptable input—what is "good enough"? Int. J. Univ. Access Inf. Soc. (Springer) 16(3), 713-723 (2017). https://doi.org/10.1007/s10209-016-0498-4

26. Honan, M.: Remembering the apple Newton's prophetic failure and lasting impact. Wired.com. 08/05/2013. https://www.wired .com/2013/08/remembering-the-apple-newtons-prophetic-failu re-and-lasting-ideals/. Accessed 27 Mar 2018 (2018) 
27. Santhanam, N.: Wii remote as a web navigation device for people with cerebral palsy. In: Proceedings of the 14th International ACM SIGACCESS Conference on Computers and Accessibility (ASSETS'12), pp. 303-304 (2012). https://doi.org/10.1145/23849 16.2385005

28. Ahmad, B.I., Murphy, J., Langdon, P.M., Godsill, S.J.: Filtering perturbed in-vehicle pointing gesture trajectories: improving the reliability of intent inference. In: Proceedings of 2014 IEEE International Workshop on Machine Learning for Signal Processing (MLSP), Reims, pp. 1-6 (2014). https://doi.org/10.1109/ MLSP.2014.6958860

29. Hwang, F., Keates, S., Langdon, P.M., Clarkson, P.J.: Movement time for motion-impaired users assisted by force-feedback: effects of movement amplitude, target width, and gravity well width. Int. J. Univ. Access Inf. Soc. (Springer) 4(2), 85-95 (2005). https:// doi.org/10.1007/s10209-005-0114-5

30. Hwang, F., Keates, S., Langdon, P., Clarkson, P.J.: A haptic toolbar for motion-impaired users. In: Proceedings of the 3rd International Conference on Universal Access in Human-Computer Interaction/11th International Conference on Human Computer Interaction. Springer, New York (2005)

31. Immersion Corporation: Form 10-Q: Quarterly report under Sect. 13 or 15(d) of the Securities Exchange Act of 1934. June 30, 2000. http://ir.immersion.com/node/14461/html. Accessed 27 Mar 2018

32. Logitech: Logitech's iFeel ${ }^{\mathrm{TM}}$ optical mice add a new dimension to the human-computer interface. Press release, 21st August 2000: https://www.logitech.com/en-roeu/press/press-releases/1183. Accessed 27 Mar 2018

33. Konishi, Y., Hanamitsu, N., Minamizawa, K., Sato, A., Mizuguchi, T.: Synesthesia suit: the full body immersive experience. In: ACM SIGGRAPH 2016 VR Village (SIGGRAPH'16). ACM, New York (2016). https://doi.org/10.1145/2929490.2932629

34. Fischer, A., Vance, J.M.: PHANToM haptic device implemented in a projection screen virtual environment. In: Proceedings of the ACM Workshop on Virtual Environments 2003 (EGVE'03), pp. 225-229 (2003). https://doi.org/10.1145/769953.769979

35. Carmichael, A., Rice, M., Sloan, D., Gregor, P.: Digital switchover or digital divide: a prognosis for usable and accessible interactive digital television in the UK. Int. J. Univ. Access Inf. Soc. 4(4), 400-416 (2006). https://doi.org/10.1007/s10209-005-0004-x

36. Keates, S., Clarkson, P.J.: Assessing the accessibility of digital television set-top boxes. In: Keates, S., Clarkson, P.J., Langdon, P.M., Robinson, P. (eds.) Design for a More Inclusive World. Springer, New York, pp. 183-192 (2004)

37. Keates, S., Adams, R., Bodine, C., Czaja, S., Gordon, W., Gregor, P., Hacker, E., Hanson, V., Kemp, J., Laff, M., Lewis, C., Pieper, M., Richards, J., Rose, D., Savidis, A., Schultz, G., Snayd, P., Trewin, S., Varker, P.: (2007) Cognitive and learning difficulties and how they affect access to IT systems. Int. J. Univ. Access Inf. Soc. (Springer) 5(4), 329-339 (2007). https://doi.org/10.1007/ s10209-006-0058-4

38. Keates, S.: A pedagogical example of teaching universal access. Int. J. Univ. Access Inf. Soc (UAIS) (Springer) 14 (1), 97-110 (2015). https://doi.org/10.1007/s10209-014-0398-4
39. Keates, S., Kyberd, P.J.: Robotic assistants for universal access. In: Antona, M., Stephanidis, C. (eds.) Universal Access in HumanComputer Interaction. Human and Technological Environments. Proceedings of UAHCI 2017. LNCS, vol. 10279. Springer, New York, pp. 527-538 (2017). https://doi.org/10.1007/978-3-31958700-4_43

40. Cooper, A.: The Inmates are Running the Asylum. SAMS Publishing, Indianapolis (1999)

41. Keates, S., Lebbon, C., Clarkson, P.J.: Investigating industry attitudes to universal design. In: Proceedings of RESNA 2000, Orlando. RESNA Press, Washington, pp. 276-278 (2000)

42. Buhler, C.: Robotics for rehabilitation-a European(?) perspective. In: Proceedings of the 5th International Conference on Rehabilitation Robotics (ICORR'97), Bath, pp. 5-11 (1997)

43. Mahoney, R.: Robotic products for rehabilitation: status and strategy. In: Proceedings of the 5th International Conference on Rehabilitation Robotics (ICORR'97), Bath, pp. 12-17 (1997)

44. Topping, M.J., Smith, J.K.: The development of handy 1. A robotic system to assist the severely disabled. Technol. Disabil. 10(2), 95-105 (1999)

45. Tijsma, H.A., Liefhebber, F., Herder, J.L.: Evaluation of new user interface features for the Manus robot arm. In: 9th International Conference on Rehabilitation Robotics (ICORR 2005), pp. 258-263. IEEE, New York (2005). https://doi.org/10.1109/ ICORR.2005.1501097

46. Gelin, R., Coulon-Lauture, F., Lesigne, B., Blanc, L., Busnel, J.-M.: Afmaster: an industrial rehabilitation workstation. In: Proceedings of International Conference on Rehabilitation Robotics (ICORR'99), pp. 149-155 (1999). http://www.rehabrobotics.org/ icorr1999/papers/papers/gelin.pdf. Accessed 27 Mar 2018

47. Keates, S., Clarkson, P.J., Robinson, P.: Developing a practical inclusive interface design approach. Interact. Comput. 14(4), 271-299 (2002). https://doi.org/10.1016/S0953-5438(01)00054-6

48. Keates, S., Clarkson, P.J., Robinson, P.: Design for participation: providing access to e-information for older adults. Int. J. Univ. Access Inf. Soc. (UAIS) (Springer) 3(2), 149-163 (2004). https ://doi.org/10.1007/s10209-004-0093-y

49. Grundy, E., Ahlburg, D., Ali, M., Breeze, E., Sloggett, A.: Disability in Great Britain. Department of Social Security. In: Research Report No. 94. Corporate Document Services, London (1999)

50. Clarkson, P.J., Keates, S., Dong, H., Clarkson, P.J., Coleman, R., Keates, S., Lebbon, C.: Quantifying Design Exclusion. Inclusive Design: Design for the Whole Population, pp. 422-437. Springer, London (2003)

51. The Inclusive Design Toolkit: https://www.inclusivedesigntoolk it.com/. Accessed 29 Jan 18 (2018)

52. Keates, S.: Pragmatic research issues confronting HCI practitioners when designing for universal access. Int. J. Univ. Access Inf. Soc. (UAIS) (Springer) 5(3), 269-278 (2006). https://doi. org/10.1007/s10209-006-0050-z

53. British Standards Institute: BS7000 Part 6: Design Management Systems. Managing Inclusive Design. British Standards Institute, Reading (2005) 